UNIVERSIDADE DE SÃO PAULO

FACULDADE DE EDUCAÇÃO

Marco Antonio da Silva

Dissertação de Mestrado

Por uma Pedagogia do Palhaço: riso, corpo jogador, transgressão e inversão

SÃO PAULO

2016 
Marco Antonio da Silva

\section{Por uma Pedagogia do Palhaço: riso, corpo jogador, transgressão e inversão}

Dissertação apresentada à Banca Examinadora como requisito parcial para obtenção do título de Mestre em Educação pela Faculdade de Educação da Universidade de São Paulo.

Área de concentração: Cultura, Organização e Educação.

Orientadora: Prof. a Dra. Patrícia Dias Prado

\section{SÃO PAULO}


AUTORIZO A REPRODUÇÃO E DIVULGAÇÃO TOTAL OU PARCIAL DESTE TRABALHO, POR QUALQUER MEIO CONVENCIONAL OU ELETRÔNICO, PARA FINS DE ESTUDO E PESQUISA, DESDE QUE CITADA A FONTE.

Catalogação na Publicação

Serviço de Biblioteca e Documentação

Faculdade de Educação da Universidade de São Paulo

$375.7 \quad$ Silva, Marco Antonio da

S586p Por uma Pedagogia do Palhaço: riso, corpo jogador, transgressão e inversão / Marco Antonio da Silva; orientação Patrícia Dias Prado. São Paulo: s. n., 2016.

183 p.; ils.

Dissertação (Mestrado - Programa de Pós-Graduação em Educação. Área de Concentração: Cultura, Organização e Educação) - Faculdade de Educação da Universidade de São Paulo.

1. Pedagogia do Palhaço 2. Riso 3. Corpo jogador 4. Transgressão 5. Inversão 6. Jogos-Educação 7. Arte-Educação I. Prado, Patrícia Dias, orient. 


\section{FOLHA DE APROVAÇÃO}

Marco Antonio da Silva

Por uma Pedagogia do Palhaço: riso, corpo jogador, transgressão e inversão.

Dissertação apresentada à Banca

Examinadora como requisito

parcial para obtenção do título de

Mestre em Educação pela

Faculdade de Educação da

Universidade de São Paulo.

Aprovado em:

Banca Examinadora:

Prof/a.Dr/a

Instituição

Assinatura

Julgamento

Prof/a.Dr/a

Instituição

Assinatura

Julgamento

Prof/a.Dr/a

Instituição

Assinatura

Julgamento 


\section{AGRADECIMENTOS}

Agradeço às potestades invisíveis que povoam a dimensão de minha intuição, que me inspiram e orientam a seguir no caminho da educação como prática da liberdade, e da arte como prática da caridade.

Agradeço aos meus pais que, por amor, me proporcionaram esta existência.

Agradeço aos/às mestres/as do passado, que nos legaram suas obras como o caminho da iniciação.

Agradeço à minha orientadora, professora Patrícia Dias Prado, pela orientação respeitosa, produtiva e amiga.

Agradeço aos professores Rogério de Almeida e Marcos Ferreira-Santos pela parceria no lab_arte e por acreditarem em meu projeto.

Agradeço àqueles que me inspiraram, que foram luz em meu caminho: ao palhaço José Carlos, meu pai (in memoriam); a contadora de histórias Maria Dalva, minha mãe; a contadora de ditos populares, Tica; aos mestres de capoeira, Pedrinho (in memoriam), Bigodinho e Pinguim; ao encenador de teatro Antunes Filho; a Tribo de Atuadores Ói Nóis Aqui Traveiz, de Porto Alegre-RS.

Agradeço aos professores que aceitaram fazer parte da banca, Mário Fernando Bolognesi (UNESP), Mônica Caldas Ehrenberg (FEUSP), Roberto da Silva (FEUSP), Rogério de Almeida (FEUSP) e Elizabeth Lopes (ECA-USP).

Agradeço aos amigos, que, graciosamente, contribuíram com a finalização desse trabalho, Alessandro Tarso e Igor Oliva.

Agradeço a Charles Spencer Chaplin porque ele existiu e nos deixou sua obra como legado e modelo de artivismo.

Agradeço às crianças e jovens com quem compartilhei e compartilho a construção de uma Pedagogia do Palhaço. 


\section{DEDICATÓRIA}

Dedico este trabalho ao Circolo Livre de Atuadores, que me proporcionou a alegria do trabalho artístico, em picadeiros, ruas, praças e parques. Muito obrigado à minha companheira Rose Vitor Bonini e aos/às nossos/as filhas/os Thamirez Mazieiro, Thais Guerra, Lana Gaia, Alice Vitor e Eros Vitor. 
Manifesto da Pedagogia do Palhaço

Cuspy or not cuspy?

That's not the question.

Falta cultura pra cuspy na estrutura.

Propomos o riso como deflagrador do pensamento sério,

E do sério como deflagrador do riso.

Riamos. Risos trágicos ou jocosos,

Mas que o primeiro seja para nós mesmos.

Haverá ainda tempo para o Alegre Saber,

Quando cada verdade contemplar uma gargalhada.

E eu, rio abaixo, rio acima,

Rio a fora, rio a dentro,

Eu rio

Marco Antonio da Silva, 2014 


\section{RESUMO}

O presente texto pretende apresentar a investigação, a partir de referenciais práticos e teóricos, sobre as possibilidades, caminhos e princípios da construção de uma Pedagogia do Palhaço, que venho desenvolvendo, desde 2000 - proposta educativa que tem como principais concepções e propostas pedagógicas as técnicas do ator-criador, do arteiro, do atuador, do artivista e do educador para a paz, que se constitui a partir dos elementos da Arte do palhaço, como o riso (enquanto deflagrador do pensamento sério), o corpo jogador, a transgressão e a inversão, na relação com a Educação, na interface com as Ciências Sociais e com as Artes, e em conformidade com minhas próprias experiências enquanto ator, palhaço, jogador de capoeira, contador/colecionador de histórias e educador. A partir da pesquisa qualitativa, através do levantamento e do estudo bibliográfico, assim como, através do método autobiográfico, selecionei materiais escritos e iconográficos sobre minha trajetória profissional e docente, problematizando-os e colocando-os sob perspectiva para a consolidação desta Pedagogia, que se aproprie do riso, do jogo e do corpo do palhaço como estratégias dialógicas; a pensar uma práxis provocadora pedagógica que caiba nos corpos dos/as profissionais que trabalham com a educação de crianças e de jovens.

Palavras-chave: Pedagogia do Palhaço, riso, corpo jogador, transgressão, inversão, arte, Educação. 


\begin{abstract}
This paper aims to present the research, based on practical and theoretical references, on the possibilities, ways and principles of the constrution of a Clown Pedagogy, I have been developing since 2000 - educational proposal whose main pedagogical conceptions and proposal are the actor-creator's techniques, the mischievous, the actuating, the "artivista" and the educator for peace, created from the Clown art's elements such as laughter (as precipitant of serious thought), the body player, transgression and inversion, in relation to Education, the interface with the Social Sciences and the Arts, and in accordance with my own experiences as an actor, clown, capoeira player, Story Teller/ Collector of stories and educator. Starting from the qualitative research through the survey and bibliographical study, as well as through the autobiographical method, I have selected written and iconographic material about my professional career and teaching, questioning them and putting them in perspective for the consolidation of this pedagogy which appropriates laugh, play and clown body as dialogical strategies; to think a pedagogical provocative práxis that fits in bodies of the professionals working with the education of children and youth.
\end{abstract}

Key words: Pedagogy Clown, laughter, body player, transgression, inversion, art, Education. 


\section{SUMÁRIO}

INTRODUÇÃO

1. Por uma Pedagogia do Palhaço...................................................... 19

1.1. A sociologia de um professor palhaço e a pesquisa

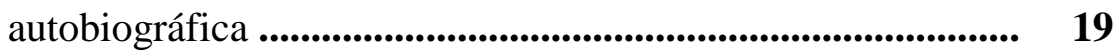

1.2. Caminhos teóricos metodológicos: Antunes Filho no divã do palhaço ............................................................................... 37

2. O jogo, pais e mestres da arte da vadiação................................. 52

2.1. Jogo e seriedade ................................................................. 56

2.2. Compreendendo melhor os jogos a partir de sua classificação $\mathbf{5 8}$

2.3. Jogo, arte e educação .................................................... $\quad 66$

3. O corpo e sua relação com o jogo ...............................................

3.1. O Corpo Jogador Consciente ............................................ $\quad 77$

3.2. A Respiração Consciente ................................................... $\quad 82$

3.3. A Voz Consciente ................................................................ 84

4. O riso e sua relação com o jogo e com o corpo .........................

4.1. Riso pedagógico: ou por uma pedagogia do riso ...... $\quad \mathbf{1 0 1}$

5. O palhaço e sua relação com o riso, com o corpo e com o jogo 107

5.1. O palhaço cotidiano .......................................................... 110

5.2. O palhaço e o corpo jogador ....................................... 118

5.3. O palhaço o que é? ....................................................... 120

6. A transgressão e sua relação com a Pedagogia do Palhaço: dos Infestas ao Circusp .....................................................................

7. A inversão e sua relação com a Pedagogia do Palhaço: ator, arteiro, atuador, artivista e educador para a paz ................................... 141

8. Considerações finais ............................................................ 175

9. Referências ............................................................................ 179 